Check for updates

Cite this: RSC Adv., 2018, 8, 7428

Received 29th November 2017 Accepted 6th February 2018

DOI: 10.1039/c7ra12874f

rsc.li/rsc-advances

\section{Assembly of a series of zinc coordination polymers based on 5-functionalized isophthalic acids and dipyridyl $\dagger$}

\author{
Tao Wang, \$ Rong-Rong Zhu, \$ Xiao-Feng Zhang, Tong Yan, Quan Wang, Jing Feng, \\ Jie Zhou, Lin Du* and Qi-Hua Zhao (D)*
}

To investigate the influence of different 5-functionalized isophthalate ligands on the self-assembly and structures of $\mathrm{Zn}(I)$-based coordination polymers (CPS), we selected four 5-functionalized isophthalate ligands coordinated with 4,4'-bipyridyl (bpy) and Zn(॥) salt, and four new CPs, namely, \{[Zn(EtOip)(bpy)]. $\left.2 \mathrm{H}_{2} \mathrm{O}\right\}_{n}$ (1), $\left\{[\mathrm{Zn}(\mathrm{PrOip})(\mathrm{bpy})] \cdot 2 \mathrm{H}_{2} \mathrm{O}\right\}_{n}(2),\left[\mathrm{Zn}\left({ }^{n} \mathrm{BuOip}\right)(\mathrm{bpy})\right]_{n}$ (3) and $\left[\mathrm{Zn}\left({ }^{n} \mathrm{PeO} \text { ip)(bpy) }\right]_{n}\right.$ (4) (where EtOip = 5-ethoxyisophthalate, PrOip $=5-n$-propoxyisophthalate, ${ }^{n}$ BuOip $=5-n$-butoxyisophthalate and ${ }^{n}$ PeOip $=5$ - $n$-pentyloxyisophthalate), were prepared under hydrothermal conditions. Moreover, we considered changing the features of the $\mathrm{N}$-ligands (length), which are expected to alter the structural diversities and properties of the resultant CPs. We used 1,2-bis(4-pyridyl)ethene (bpe) to replace bpy; and obtained four new coordination polymers (CPs), namely, $\left\{\left[\mathrm{Zn}(\text { EtOip)(bpe) }] \cdot \mathrm{H}_{2} \mathrm{O}\right\}_{n}(5),\left\{[\mathrm{Zn}(\operatorname{PrOip})(\mathrm{bpe})] \cdot \mathrm{H}_{2} \mathrm{O}\right\}_{n}(6)\right.$, $\left\{\left[Z n\left({ }^{n} \mathrm{BuOip}\right)(\mathrm{bpe})\right] \cdot 0.5 \mathrm{DMF}\right\}_{n}(7)$ and $\left[\mathrm{Zn}\left({ }^{n} \mathrm{PeO} \mathrm{ip}\right)(\mathrm{bpe})\right]_{n}(8)$. All of these compounds were characterized by single crystal $\mathrm{X}$-ray diffraction, infrared spectroscopy, elemental analysis and powder $\mathrm{X}$-ray diffraction measurements. Single-crystal $X$-ray analysis reveals that the structure of complexes 1-4 are very similar, although different functionalized-isophthalate ligands are employed. Complexes 5, 6 and 7 possess a two-dimensional (2D) layered structure, and the 2D framework of complexes 5 and 7 can be rationalized to be a threefold interpenetrating four-connected $\left\{4^{4} \cdot 6^{2}\right\}$ topological sql network, while 6 exhibits a twofold interpenetrating 4-connected 2D framework. Compound 8 features a 6 -connected $3 \mathrm{D}$ topology net based on a novel bimetallic unit $\left[(\mathrm{Zn})_{2}\left(\mathrm{CO}_{2}\right)_{2}\right]$ linked by mixed ${ }^{n}$ PeOip and bpe ligands. Moreover, thermal and photoluminescence properties of the synthesized complexes were also studied in detail.

\section{Introduction}

Over the past few decades, the rational design and synthesis of novel coordination polymers (CPs) has been of great interest in coordination chemistry and material science due to the intriguing architectures and topologies of the CPs, but also for their potential applications as functional materials in numerous fields, such as luminescence, catalysis, gas adsorption/separation, magnetism and so forth ${ }^{\mathbf{1 - 1 3}}$ Despite that a comparatively large number of interesting coordination polymers with intricate structural architectures have been reported to date, the design and construction of multi-functional

Key Laboratory of Medicinal Chemistry for Natural Resource Education Ministry, School of Chemical Science and Technology - Pharmacy, Yunnan University, Kunming, 650091, PR China.E-mail: qhzhao@ynu.edu.cn; lindu@ynu.edu.cn

$\dagger$ Electronic supplementary information (ESI) available: Crystal data, crystal structures, powder X-ray diffraction patterns and IR spectra. CCDC 1557106-1557109 for 1-4, 1557102-1557105 for 5-8. For ESI and crystallographic data in CIF or other electronic format see DOI: 10.1039/c7ra12874f

\$ These authors contributed equally to this paper.
CPs with desired structures and properties remains a significant challenge for chemists. This is because many intrinsic and external factors, such as the coordination nature of the metal centers, the structural characteristics of the organic ligands, stoichiometry, temperature, solvent, the $\mathrm{pH}$ of the solution and so on, may considerably influence the formation of the resulting CPs. ${ }^{14-22}$ Of all the influencing factors, the deliberate selection of functionalized organic ligands plays a crucially important role in the structural assembly process, and in some cases, a subtle alteration of organic motifs may lead to a novel architecture. ${ }^{23-25}$

In recent years, functionalized polycarboxylic acid derivatives have been extensively used as multifunctional organic ligands in the formation of coordination frameworks owing to their high stability, various coordination modes and strong coordination ability toward transition metal ions. ${ }^{26-30}$ Among them, 5-functionalized isophthalates are good candidates within coordination and supramolecular chemistry because their two V-shaped carboxylate groups may bridge metal ions or metal clusters via versatile coordination modes similar to that of isophthalate. ${ }^{31-40}$ For example, McCormick et al. found that the topology of CPs is dependent on the combination of solvent 
system used and length of the functionalized-groups. ${ }^{39}$ The studies of Sha et al. indicated that the adsorption capacity of water, methanol and ethanol can be effectively tuned through changing the functionalized-groups. ${ }^{40} \mathrm{Up}$ to now, a large number of CPs based on 5-functionalized isophthalate derivatives have been reported by several groups. However, studies on the effect of long alkoxy chain functionalized-groups on the phenolic oxygen atom in the formation of the resultant CPS remain scarce so far.

In addition, the introduction of $\mathrm{N}$-containing ligands into the carboxylate systems may exert a significant influence on the assembly process of CPs. Previous studies have demonstrated that N-donor auxiliary ligands can provide cooperative coordination together with the carboxylate group to satisfy the requirements of the coordination geometries of the metal ions in the assembly process. Bipyridyl ligands, such as $4,4^{\prime}$-bipyridyl (bpy) ${ }^{41-50}$ and 1,2-bis(4-pyridyl)ethene (bpe) 11-43,51-61 $^{\text {have been }}$ extensively used as ancillary ligands in the controllable synthesis of CPs.

Inspired from the above-mentioned, we therefore selected four 5-functionalized isophthalate ligands with different numbers of carbon atoms, which are 5-ethoxyisophthalate (EtOip), 5- $n$-propoxyisophthalate (PrOip), 5- $n$-butoxyisophthalate ( ${ }^{n}$ BuOip) and 5- $n$-pentyloxyisophthalate $\left({ }^{n}\right.$ PeOip) and neutral $\mathrm{N}$-donor ligands 4,4'-bipyridine (bpy) and 1,2-bis(4pyridyl)ethane (bpe) as an organic building blocks. Eight new Zn CPs, namely, $\quad\left\{\left[\mathrm{Zn}(\text { EtOip)(bpy) }] \cdot 2 \mathrm{H}_{2} \mathrm{O}\right\}_{n}\right.$ $\left\{[\mathrm{Zn} \text { (PrOip)(bpy) }] \cdot 2 \mathrm{H}_{2} \mathrm{O}\right\}_{n} \quad(2), \quad\left[\mathrm{Zn}\left({ }^{n} \text { BuOip)(bpy) }\right]_{n}\right.$ $\left[\mathrm{Zn}\left({ }^{n} \text { PeOip)(bpy) }\right]_{n} \quad(\mathbf{4}), \quad\left\{[\mathrm{Zn}(\text { EtOip)(bpe })] \cdot \mathrm{H}_{2} \mathrm{O}\right\}_{n}\right.$ (3), and $\left[\mathrm{Zn}\left({ }^{n} \mathrm{PeOip}\right)(\mathrm{bpe})\right]_{n}(8)$, have been (Zno ( PeOip)(bpe) $]_{n}$ (8), have been synthesized under hydrothermal conditions. Their structural diversities reveal that different functionalized groups and the length of dipyridyl ligands play an important role in the self-assembly processes. All compounds were characterized by single-crystal X-ray diffraction, infrared spectra (IR), elemental analyses and powder X-ray diffraction (PXRD). Furthermore, thermal and photoluminescence properties of the synthesized complexes were also studied in detail.

\section{Experimental}

\section{Materials and methods}

The ligands $\mathrm{H}_{2}$ EtOip, $\mathrm{H}_{2}$ PrOip, $\mathrm{H}_{2}{ }^{n}$ BuOip and $\mathrm{H}_{2}{ }^{n}$ PeOip were synthesized according to a method in the literature. ${ }^{39,62}$ Other reagents and solvents were commercially available and were used without further purification. Elemental analyses for $\mathrm{C}, \mathrm{H}$, and $\mathrm{N}$ were carried out using an Elementar Vario ELIII analyzer. IR spectra were recorded on a FT-IR Thermo Nicolet Avatar 360 using $\mathrm{KBr}$ pellets in the $400-4000 \mathrm{~cm}^{-1}$ region. All powder X-ray diffraction (PXRD) analyses were recorded on a Rigaku D/M$2200 \mathrm{~T}$ automated diffractometer $(\mathrm{CuK} \alpha, 1.5418 \AA)$. Thermal stability studies were carried out on a NETZSCH STA-449C thermoanalyzer with a heating rate of $10{ }^{\circ} \mathrm{C} \min ^{-1}$ under a nitrogen atmosphere. All fluorescence measurements were performed on an Edinburgh Instrument F920 spectrometer.

\section{Synthesis procedures}

Preparation of $\left\{\left[\mathrm{Zn}(\text { EtOip)(bpy) }] \cdot 2 \mathrm{H}_{2} \mathrm{O}\right\}_{n}\right.$ (1). A mixture of $\mathrm{H}_{2}$ EtOip (21 $\left.\mathrm{mg}, 0.1 \mathrm{mmol}\right)$, bpy $(15.6 \mathrm{mg}, 0.1 \mathrm{mmol}$ ), $\mathrm{Zn}\left(\mathrm{NO}_{3}\right)_{2} \cdot 6 \mathrm{H}_{2} \mathrm{O}(30 \mathrm{mg}, 0.1 \mathrm{mmol})$ dissolved in DMF $(1.0 \mathrm{~mL})$ and $\mathrm{H}_{2} \mathrm{O}(4.0 \mathrm{~mL})$ were placed in a $15 \mathrm{~mL}$ Teflon-lined stainless steel autoclave and heated at $120{ }^{\circ} \mathrm{C}$ for two days. After the mixture was cooled to ambient temperature at a rate of $5{ }^{\circ} \mathrm{C} \mathrm{h}^{-1}$, pink block crystals of 1 were obtained with a yield of $46 \%$ (based on $\mathrm{Zn}$ ). Anal. calcd for $\mathrm{C}_{20} \mathrm{H}_{20} \mathrm{~N}_{2} \mathrm{O}_{7} \mathrm{Zn}$ : C, 51.57\%; H, 4.33\%; N, $6.02 \%$. Found: C, 51.63\%; H, 4.41\%; N, 6.06\%. IR (KBr, $\left.\mathrm{cm}^{-1}\right)$ : 3474(vs), 2932(w), 2868(w), 1620(s), 1589(w), 1506(w), 1409(s), $1347(\mathrm{w}), 1261(\mathrm{w}), 1227(\mathrm{w}), 1122(\mathrm{~m}), 1068(\mathrm{w}), 1028(\mathrm{w}), 929(\mathrm{w})$, 844(w), 779(w), 731(m).

Preparation of $\left\{\left[\mathrm{Zn}(\text { PrOip)(bpy) }] \cdot \mathbf{2 H}_{2} \mathbf{O}\right\}_{n}\right.$ (2). The procedures for the syntheses of $\mathbf{2}$ were similar to that used for $\mathbf{1}$, except that $\mathrm{H}_{2}$ PrOip (22 mg, $0.1 \mathrm{mmol}$ ) was used instead of $\mathrm{H}_{2}$ EtOip. Pink block crystals of 2 were obtained with a yield of $56 \%$ (based on $\mathrm{Zn}$ ). Anal. calcd for $\mathrm{C}_{21} \mathrm{H}_{22} \mathrm{~N}_{2} \mathrm{O}_{7} \mathrm{Zn}: \mathrm{C}, 52.57 \% ; \mathrm{H}, 4.62 \%$; 5.84\%. Found: C, 52.46\%; H, 4.57\%; N, 5.68\%. IR (KBr, $\left.\mathrm{cm}^{-1}\right)$ : 3417(vs), 2967(w), 1618(s), 1574(w), 1491(w), 1418(s), 1320(w), 1264(w), 1220(w), 1121(m), 1089(w), 1013(w), 914(w), 875(w), $777(\mathrm{w}), 729(\mathrm{~m}), 641(\mathrm{w})$.

Preparation of $\left[\mathrm{Zn}\left({ }^{n} \mathrm{BuOip}\right)(\mathrm{bpy})\right]_{n}$ (3). The procedures for the syntheses of 3 were similar to that used for $\mathbf{1}$, except that $\mathrm{H}_{2}$ ${ }^{n}$ BuOip (22 mg, $0.1 \mathrm{mmol}$ ) was used instead of $\mathrm{H}_{2}$ EtOip. Colourless block crystals of 3 were obtained with a yield of $60 \%$ (based on $\mathrm{Zn}$ ). Anal. calcd for $\mathrm{C}_{22} \mathrm{H}_{20} \mathrm{~N}_{2} \mathrm{O}_{5} \mathrm{Zn}$ : C, $57.72 \% ; \mathrm{H}$, $4.40 \%$; N, 6.12\%. Found: C, 57.67\%; H, 4.36\%; N, 6.15\%. IR $\left(\mathrm{KBr}, \mathrm{cm}^{-1}\right): \quad 3414(\mathrm{vs}), 2957(\mathrm{w}), 2870(\mathrm{w}), 1611(\mathrm{~s}), \quad 1549(\mathrm{w})$, 1487(w), 1420(s), 1320(w), 1268(w), 1220(w), 1123(m), 1099(w), 1015(w), 992(w), 854(w), 781(w), 736(m), 678(w), 637(w).

Preparation of $\left[\mathbf{Z n}\left({ }^{n} \text { PeOip)(bpy) }\right]_{n}(\mathbf{4})\right.$. The procedures for the syntheses of $\mathbf{4}$ were similar to that used for $\mathbf{1}$, except that $\mathrm{H}_{2}$ ${ }^{n}$ PeOip (22 mg, $0.1 \mathrm{mmol}$ ) was used instead of $\mathrm{H}_{2}$ EtOip. Colourless block crystals of 8 were obtained with a yield of $54 \%$ (based on $\mathrm{Zn}$ ). Anal. calcd for $\mathrm{C}_{23} \mathrm{H}_{22} \mathrm{~N}_{2} \mathrm{O}_{5} \mathrm{Zn}$ : C, 58.55\%; $\mathrm{H}$, 4.70\%; N, 5.94\%. Found: C, 58.57\%; H, 4.63\%; N, 5.86\%. IR $\left(\mathrm{KBr}, \mathrm{cm}^{-1}\right): \quad 3438(\mathrm{vs}), 2923(\mathrm{w}), 2857(\mathrm{w}), 1622(\mathrm{w}), 1611(\mathrm{~s})$, 1568(w), 1488(w), 1391(s), 1321(w), 1263(w), 1223(w), 1118(m), 1078(w), 1017(w), 824(w), 781(w), 639(w).

Preparation of $\left\{\left[\mathrm{Zn}(\text { EtOip)(bpe) }] \cdot \mathbf{H}_{2} \mathrm{O}\right\}_{n}\right.$ (5). Compound 5 was prepared by using a method similar to that used for the preparation of 1 , except that bpe $(18 \mathrm{mg}, 0.1 \mathrm{mmol})$ were used instead of bpy. Colourless block crystals of 5 were obtained with a yield of $59 \%$ (based on $\mathrm{Zn}$ ). Anal. calcd for $\mathrm{C}_{22} \mathrm{H}_{20} \mathrm{~N}_{2} \mathrm{O}_{6} \mathrm{Zn}$ : C, $55.77 \%$; H, 4.26\%; N, 5.91\%. Found: C, 55.69\%; H, 4.18\%; N, $5.86 \%$. IR (KBr, $\left.\mathrm{cm}^{-1}\right)$ : 3516(vs), 2924(w), 2880(w), 1615(s), $1580(\mathrm{w}), 1508(\mathrm{w}), 1477(\mathrm{~s}), 1435,1342(\mathrm{w}), 1262(\mathrm{w}), 1207(\mathrm{w})$, 1118(m), 1031(w), 936(w), 777(w), 733(m).

Preparation of $\left\{[\mathrm{Zn}(\mathrm{PrOip})(\mathrm{bpe})] \cdot \mathrm{H}_{2} \mathrm{O}\right\}_{n}$ (6). Compound 6 was prepared by using a method similar to that used for the preparation of 2 , except that bpe $(18 \mathrm{mg}, 0.1 \mathrm{mmol})$ were used instead of bpy. Colourless block crystals of 6 were obtained with a yield of $52 \%$ (based on $\mathrm{Zn}$ ). Anal. calcd for $\mathrm{C}_{23} \mathrm{H}_{22} \mathrm{~N}_{2} \mathrm{O}_{6} \mathrm{Zn}$ : C, $56.63 \%$; H, 4.55\%; N, 5.74\%. Found: C, 56.65\%; H, 4.53\%; N, $5.68 \%$. IR (KBr, $\left.\mathrm{cm}^{-1}\right)$ : 3466(vs), 2959(w), 2878(w), 1613(s), 
1587(w), 1450(w), 1404(s), 1337(w), 1262(w), 1203(w), 1121(m), 1026(w), 963(w), 843(w), 777(w), 730(m).

Preparation of $\left\{\left[\mathrm{Zn}\left({ }^{n} \mathrm{BuOip}\right)(\mathrm{bpe})\right] \cdot 0.5 \mathrm{DMF}\right\}_{\boldsymbol{n}}$ (7). Compound 7 was prepared by using a method similar to that used for the preparation of 3 , except that bpe $(18 \mathrm{mg}, 0.1 \mathrm{mmol})$ were used instead of bpy. Colourless block crystals of 7 were obtained with a yield of $36 \%$ (based on $\mathrm{Zn}$ ). Anal. calcd for $\mathrm{C}_{24} \mathrm{H}_{22} \mathrm{~N}_{2} \mathrm{O}_{5} \mathrm{Zn}$ : C, $59.58 \%$; H, 4.58\%; N, 5.79\%. Found: C, 59.53\%; H, 4.62\%; N, 5.76\%. IR (KBr, $\left.\mathrm{cm}^{-1}\right)$ : 3439(vs), 2933(w), 2868(w), 1679(s), 1613(s), 1578(w), 1474(w), 1434(s), 1344(w), 1262(w), 1206(w), 1119(w), 1069(w), 992(w), 835(w), 780(w), 732(m), 694(w), 621(w).

Preparation of $\left[\mathrm{Zn}\left({ }^{n} \text { PeOip)(bpe }\right)\right]_{n}$ (8). Compound 8 was prepared by using a method similar to that used for the preparation of 4 , except that bpe $(18 \mathrm{mg}, 0.1 \mathrm{mmol})$ were used instead of bpy. Colourless block crystals of 8 were obtained with a yield of $61 \%$ (based on $\mathrm{Zn}$ ). Anal. calcd for $\mathrm{C}_{19} \mathrm{H}_{19} \mathrm{NO}_{5} \mathrm{Zn}$ : C, $56.10 \%$; H, 4.71\%; N, 3.44\%. Found: C, 56.08\%; H, 4.65\%; N, $3.34 \%$. IR (KBr, $\left.\mathrm{cm}^{-1}\right)$ : 3446(vs), 2953(w), 2868(w), 1614(s), 1563(w), 1453(w), 1358(s), 1320(w), 1266(w), 1209(w), 1123(m), 1104(w), 1044(w), 841(w), 781(w), 726(m).

\section{X-ray data collection and structure determination}

Single-crystal X-ray diffraction data for 1-8 were collected on a Bruker SMART APEX II CCD diffractometer equipped with graphite-monochromated Mo-K $\alpha(\lambda=0.71073 \AA)$ by using the $\Phi / \omega$ scan technique. Absorption correction was based on symmetry equivalent reflections by using the SADABS program. ${ }^{63}$ The crystal structures of 1-8 were solved by direct methods and refined on $F^{2}$ by full-matrix least-squares methods with the SHELXL-2014 program. ${ }^{64}$ All non-hydrogen atoms were refined anisotropically. The $\mathrm{H}$ atoms of the solvent water molecule in 1, 2, 5 and $\mathbf{6}$ were located from the Fourier map and included in the final refinement by use of geometrical restraints with the $\mathrm{O}-\mathrm{H}$ distances being fixed at $0.85 \AA$ and $U_{\text {iso }}(\mathrm{H})$ equivalent to 1.5 times of $U_{\text {eq }}(\mathrm{O})$. All of the other $\mathrm{H}$ atoms were introduced at the calculated positions and included in the structure-factor calculations. The highly disordered DMF molecules in 7 were removed using the SQUEEZE procedure in PLATON. ${ }^{65}$ The number of DMF molecules was obtained on the basis of elemental and thermogravimetric analyses. The disordered $\mathrm{C}$ and $\mathrm{O}$ atoms of the EtOip ligands in compound $\mathbf{1}$ (C19, $\mathrm{C}^{\prime} 9^{\prime}, \mathrm{C} 20, \mathrm{C} 20^{\prime}, \mathrm{O} 5, \mathrm{O}^{\prime}$ ), the disordered $\mathrm{C}$ and $\mathrm{O}$ atoms of the PrOip ligands in compound 2 (C19, C19', C20, C20', C21, C21', $\left.\mathrm{O} 5, \mathrm{O}^{\prime}\right)$, the disordered $\mathrm{C}$ atoms of the bpy ligands in compound $4\left(\mathrm{C} 1, \mathrm{C} 1^{\prime}, \mathrm{C} 2, \mathrm{C} 2^{\prime}, \mathrm{C} 4, \mathrm{C} 4^{\prime}, \mathrm{C} 5, \mathrm{C} 5^{\prime}\right)$ and the disordered $\mathrm{O}$ atoms of the water molecules in compound 1 (O2W, $\left.\mathrm{O} 2 \mathrm{~W}^{\prime}\right)$ were refined using $\mathrm{O}$ atom split over two sites, with a total occupancy of 1. A summary of key crystallographic information for 1-8 is given in Table 1. Selected bond lengths and angles for 1-8 are listed in Table $\mathrm{S} 1 . \dagger$

\section{Results and discussion}

\section{Crystal structures of 1 and 2}

Single-crystal XRD analysis revealed that the structures of $\mathbf{1}$ and 2 are highly similar, and thus can be treated together. The asymmetric units of 1 (Fig. 1a) and 2 (Fig. 1b) contain one Zn(II) ion, one bpy ligand, two water solvent molecules and one EtOip ligand for $\mathbf{1}$ or one PrOip ligand for 2 . Each $\mathrm{Zn}$ center is coordinated by two nitrogen atoms from two different bpy ligands and two oxygen atoms from two different EtOip ligands for $\mathbf{1}$ or PrOip ligands for 2. The $\mathrm{Zn}$ atoms are connected by bpy ligands to form an infinite 1D zigzag $[\mathrm{Zn}(\mathrm{bpy})]_{n}$ chain running along the $b$ axis (Fig. S1 $\dagger$ ). Each 1D chain further bridges its equivalent ones via EtOip (1) or PrOip (2) along the $c$ axis and finally affords a 2D coordination polymer network (Fig. 1c and d). In 1 and 2, both EtOip and PrOip molecule adopt a bis-monodentate coordination mode (Scheme 1(I)). The

Table 1 Crystallographic data and structure refinement summary for compounds 1-8

\begin{tabular}{|c|c|c|c|c|c|c|c|c|}
\hline Compound & 1 & 2 & 3 & 4 & 5 & 6 & 7 & 8 \\
\hline Formula & $\mathrm{C}_{20} \mathrm{H}_{20} \mathrm{~N}_{2} \mathrm{O}_{7} \mathrm{Zn}$ & $\mathrm{C}_{21} \mathrm{H}_{22} \mathrm{~N}_{2} \mathrm{O}_{7} \mathrm{Zn}$ & $\mathrm{C}_{22} \mathrm{H}_{20} \mathrm{~N}_{2} \mathrm{O}_{5} \mathrm{Zn}$ & $\mathrm{C}_{23} \mathrm{H}_{22} \mathrm{~N}_{2} \mathrm{O}_{5} \mathrm{Zn}$ & $\mathrm{C}_{22} \mathrm{H}_{20} \mathrm{~N}_{2} \mathrm{O}_{6} \mathrm{Zn}$ & $\mathrm{C}_{23} \mathrm{H}_{22} \mathrm{~N}_{2} \mathrm{O}_{6} \mathrm{Zn}$ & $\mathrm{C}_{24} \mathrm{H}_{22} \mathrm{~N}_{2} \mathrm{O}_{5} \mathrm{Zn}$ & $\mathrm{C}_{19} \mathrm{H}_{19} \mathrm{NO}_{5} \mathrm{Zn}$ \\
\hline Formula weight & 465.75 & 479.77 & 457.77 & 471.81 & 473.77 & 487.79 & 483.80 & 406.72 \\
\hline Crystal system & Monoclinic & Monoclinic & Orthorhombic & Orthorhombic & Monoclinic & Triclinic & Triclinic & Monoclinic \\
\hline Space group & $P 2_{1} / n$ & $P 2_{1} / n$ & Pbca & Cmce & $P 2_{1} / c$ & $P \overline{1}$ & $P \overline{1}$ & $C 2 / c$ \\
\hline$a(\AA)$ & $7.9207(7)$ & $7.9431(7)$ & $13.5909(16)$ & $18.696(2)$ & $8.6150(15)$ & $9.5648(16)$ & $8.482(7)$ & $16.6370(16)$ \\
\hline$b(\AA)$ & $15.0598(13)$ & $15.5159(14)$ & $15.3382(18)$ & $14.2482(17)$ & $26.006(4)$ & $11.4815(16)$ & $10.245(8)$ & $9.2945(9)$ \\
\hline$c(\AA)$ & $17.2160(14)$ & $17.2037(16)$ & $19.411(2)$ & 16.1635(19) & $10.0175(17)$ & $11.5626(16)$ & $15.967(12)$ & $24.212(2)$ \\
\hline$\alpha\left(^{\circ}\right)$ & 90 & 90 & 90 & 90 & 90 & $100.477(2)$ & $99.022(10)$ & 90 \\
\hline$\beta\left(^{\circ}\right)$ & $99.0770(10)$ & $99.5690(10)$ & 90 & 90 & $113.667(2)$ & $100.808(2)$ & $93.005(10)$ & $94.950(1)$ \\
\hline$\gamma\left({ }^{\circ}\right)$ & 90 & 90 & 90 & 90 & 90 & $113.570(2)$ & $114.363(9)$ & 90 \\
\hline$V\left(\AA^{3}\right)$ & $2027.9(3)$ & $2090.8(3)$ & $4046.4(8)$ & $4305.7(9)$ & $2055.6(6)$ & $1095.7(3)$ & $1237.7(17)$ & $3730.0(6)$ \\
\hline$Z$ & 4 & 4 & 8 & 8 & 4 & 2 & 2 & 8 \\
\hline$D_{\text {calcd }}\left(\mathrm{g} \mathrm{cm}^{-3}\right)$ & 1.526 & 1.524 & 1.503 & 1.456 & 1.531 & 1.479 & 1.298 & 1.449 \\
\hline$\mu\left(\mathrm{mm}^{-1}\right)$ & 1.256 & 1.221 & 1.251 & 1.178 & 1.24 & 1.16 & 1.03 & 1.35 \\
\hline$F(000)$ & 960.0 & 992.0 & 1888.0 & 1952.0 & 976 & 504 & 500 & 1680 \\
\hline$R_{1}[I>2 \sigma(I)]$ & 0.0329 & 0.0338 & 0.0457 & 0.0704 & 0.0487 & 0.0399 & 0.0396 & 0.0321 \\
\hline $\mathrm{w} R_{2}[I>2 \sigma(I)]$ & 0.0876 & 0.0809 & 0.0914 & 0.1897 & 0.0975 & 0.0825 & 0.0851 & 0.0809 \\
\hline$R_{1}$ (all data) & 0.0401 & 0.0460 & 0.1146 & 0.0950 & 0.0980 & 0.0618 & 0.0543 & 0.0403 \\
\hline $\mathrm{w} R_{2}$ (all data) & 0.0913 & 0.0878 & 0.1153 & 0.2004 & 0.1112 & 0.0896 & 0.0905 & 0.0848 \\
\hline GOF on $F^{2}$ & 1.10 & 1.03 & 0.99 & 1.09 & 0.98 & 1.02 & 0.97 & 1.07 \\
\hline CCDC number & 1557106 & 1557107 & 1557108 & 1557109 & 1557102 & 1557103 & 1557104 & 1557105 \\
\hline
\end{tabular}


(a)

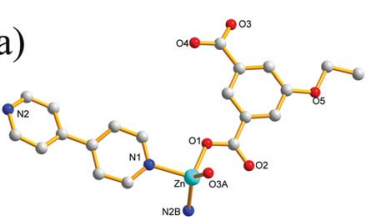

(b)

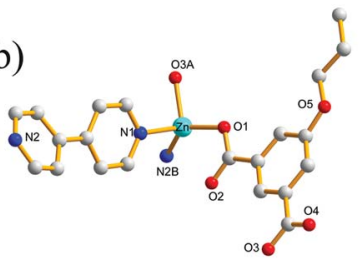

(c)

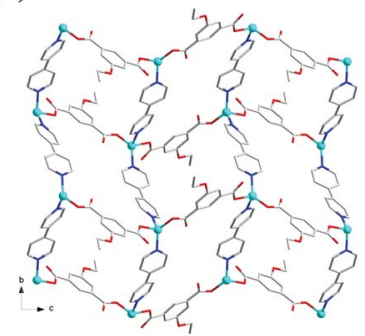

(d)

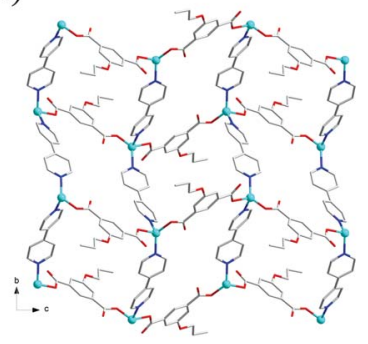

Fig. 1 (a) Coordination environment of the Zn(॥) centers in 1 with the hydrogen atoms and solvent molecules omitted for clarity (symmetric codes: (A) $x-1 / 2,-y+3 / 2, z-1 / 2$ and (B) $-x-1 / 2, y+1 / 2,-z+1 / 2$ ). (b) Coordination environment of the $\mathrm{Zn}(\mathrm{II})$ centers in 2 with the hydrogen atoms and solvent molecules omitted for clarity (symmetric codes: (A) $x+1 / 2,-y+3 / 2, z+1 / 2$ and (B) $-x+1 / 2, y+1 / 2,-z+1 / 2$ ). (c) View of the 2D [Zn(EtOip)(bpy) $]_{n}$ network of 1. (d) View of the $2 \mathrm{D}$ $[\mathrm{Zn}(\mathrm{PrOip})(\mathrm{bpy})]_{n}$ network of 2.

$\mathrm{Zn} \cdots \mathrm{Zn}$ distance bridged by the 5 -functionalized isophthalate linker is 9.3887(8) $\AA$ for $\mathbf{1}$ and 9.4095(8) $\AA$ for 2, whereas the $\mathrm{Zn} \cdots$ Zn distance bridged by bpy ranges from $10.9766(8) \AA$ to $10.9512(8)$ $\AA$. Topological analysis reveals that both frameworks can be represented as a uninodal 4-connected sql/Shubnikov tetragonal plane net with the point symbol $\left\{4^{4} \cdot 6^{2}\right\}$.

\section{Crystal structure of 3}

Crystal structure determination reveals that complex 3 crystallizes in the orthorhombic space group $P b c a$ and its asymmetric unit bears one $\mathrm{Zn}$ (II) ion, one bpy ligand and one ${ }^{n}$ BuOip ligand. As shown in Fig. $2 \mathrm{a}$, the $\mathrm{Zn}$ center is five-coordinated with three carboxylate oxygen atoms from two ${ }^{n}$ BuOip ligands and two nitrogen atoms derived from two different bpy ligands, thereby resulting a distorted trigonal bipyramidal coordination $\left[\mathrm{ZnN}_{2} \mathrm{O}_{3}\right]$ geometry. The lengths of the $\mathrm{Zn}-\mathrm{O}$ [1.935(2)-2.037(2) $\AA]$ and $\mathrm{Zn}-\mathrm{N}$ [2.067(3)-2.120(3) $\mathrm{A}]$ bonds are comparable with those observed in other related compounds containing $\mathrm{O}-\mathrm{Zn}-\mathrm{N}$ segments. Each ${ }^{n}$ BuOip ligand in 3 bridges two $\mathrm{Zn}$ centres via chelating and monodentate carboxylate groups (Scheme 1(II)) to generate a $1 \mathrm{D}\left[\mathrm{Zn}^{n} \mathrm{BuOip}\right]_{n}$ chain along the $c$ axis (Fig. S2 $\uparrow$ ). The adjacent $\left[\mathrm{Zn}^{n} \text { BuOip }\right]_{n}$ chains are linked by bpy to yield a $2 \mathrm{D}$ wrinkled layer of $\left[\mathrm{Zn}\left({ }^{n} \mathrm{BuOip}\right)(\mathrm{bpy})\right]_{n}$ extending in the $b c$ plane (Fig. 2b). Topological analysis reveals that the network can also be viewed as a 4 -connected sql/Shubnikov tetragonal plane net with the point symbol $\left\{4^{4} \cdot 6^{2}\right\}$.

\section{Crystal structure of 4}

Compound 4 crystallizes in the orthorhombic with Cmca space group. The asymmetric unit of the title compound comprises one $\mathrm{Zn}$ (II) ion, half of a ${ }^{n}$ PeOip linker, as well as half of a bpy

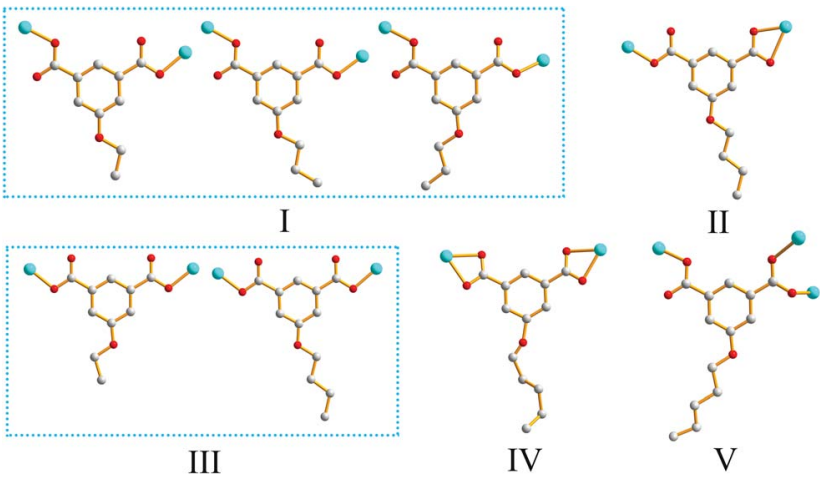

Scheme 1 Coordination modes of the 5-functionalized isophthalate ligands used in this work.

ligand. As shown in Fig. 3a, the six-coordinate $\mathrm{Zn}$ (II) ion possesses a distorted octahedral $\left[\mathrm{ZnN}_{2} \mathrm{O}_{4}\right]$ geometry, which is completed by four carboxylate oxygen atoms from two ${ }^{n} \mathrm{PeOip}$ ligands and two nitrogen atoms coming from two bpy ligands. The $\mathrm{Zn}-\mathrm{O}[2.173(4)-2.192(4) \AA]$ and $\mathrm{Zn}-\mathrm{N}[2.104(4) \AA]$ distances are within reasonable ranges reported for other related $\mathrm{Zn}(\mathrm{II})$
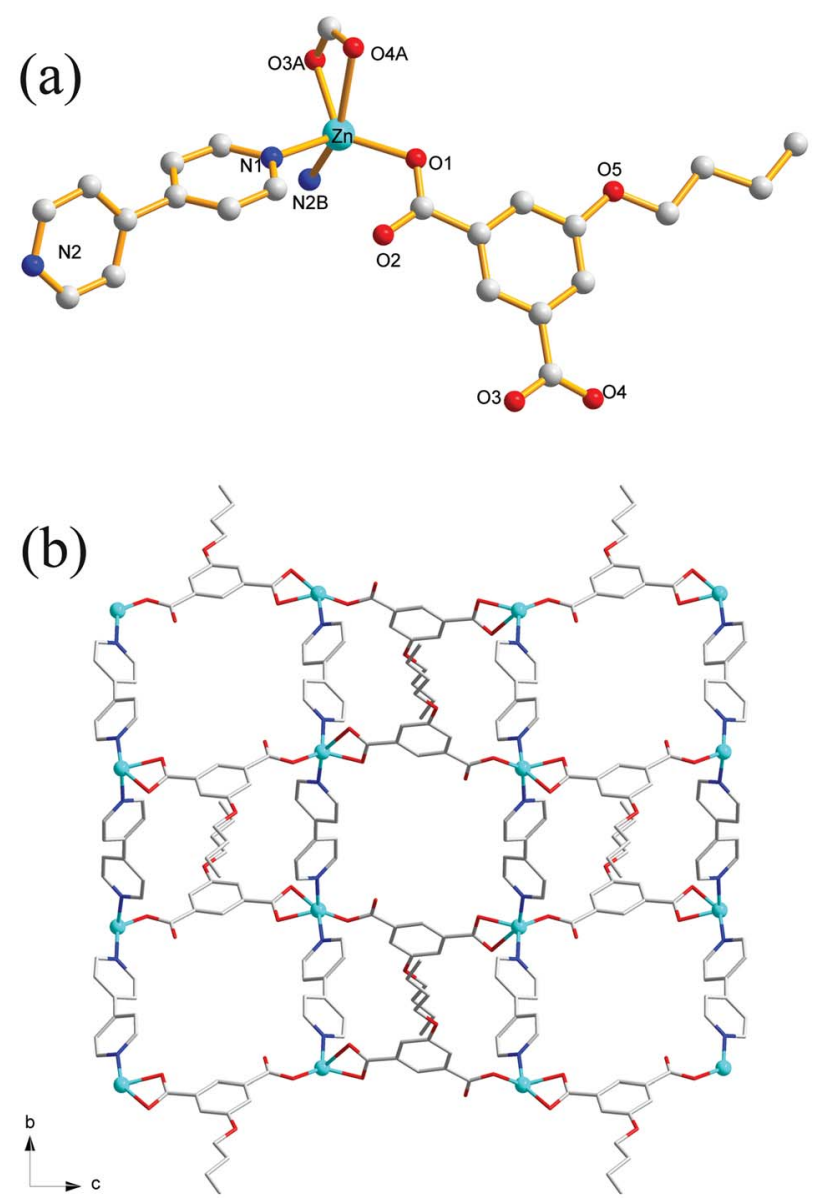

Fig. 2 (a) Coordination environment of the Zn(॥) centers in 3 with the hydrogen atoms omitted for clarity (symmetric codes: (A) $x,-y+1 / 2, z$ $+1 / 2$ and (B) $-x+1, y-1 / 2,-z+1 / 2$ ). (b) View of the $2 D$ $\left[\mathrm{Zn}\left({ }^{n} \mathrm{BuOip}\right)(\mathrm{bpy})\right]_{n}$ network of 3 . 
(a)

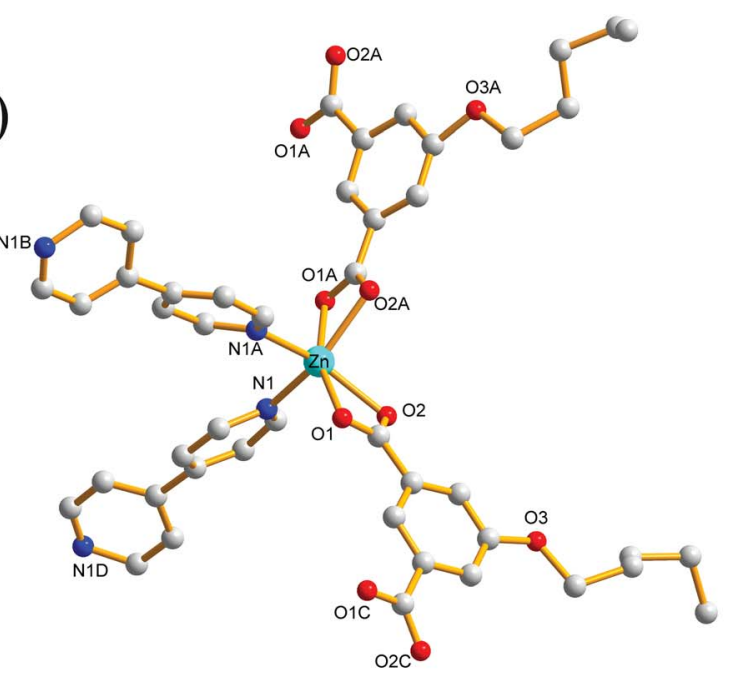

(b)

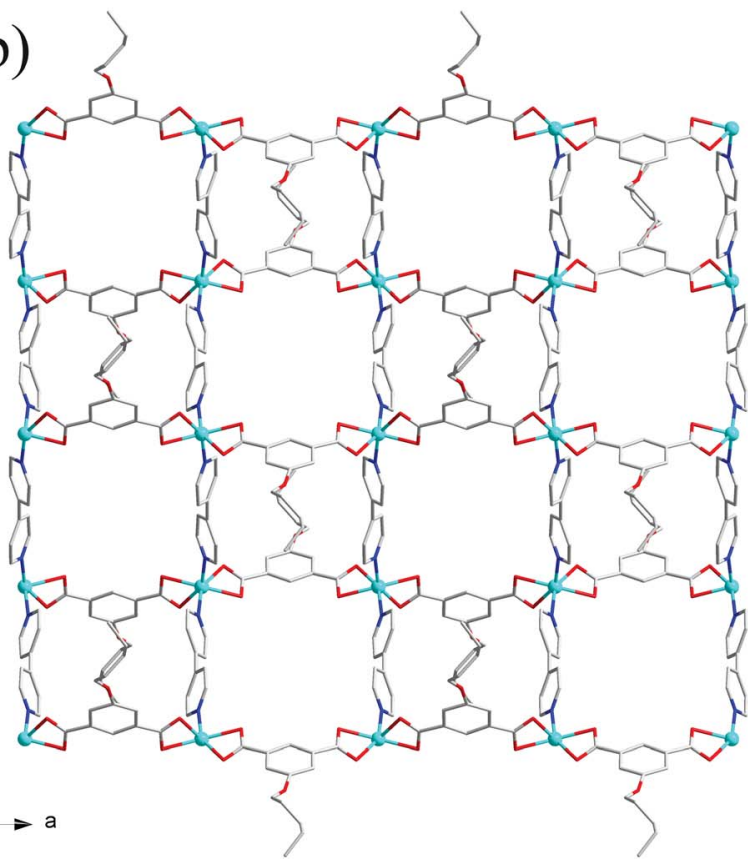

Fig. 3 (a) Coordination environment of the $\mathrm{Zn}($ II) centers in 4 with the hydrogen atoms omitted for clarity (symmetric codes: (A) $-x+1 / 2, y$, $-z+1 / 2$; (B) $1 / 2-x, 1-y,-1 / 2+z$; (C) $1-x, y, z$ and (D) $x, 1-y, 1-z$ ). (b) View of the $2 \mathrm{D}\left[\mathrm{Zn}\left({ }^{n} \mathrm{PeO} \text { ip)(bpy) }\right]_{n}\right.$ network of 4

compounds. Each ${ }^{n}$ PeOip connects two $\mathrm{Zn}$ atoms via chelating bis(bidentate) coordination mode (Scheme 1(IV)) to give an infinite $1 \mathrm{D}$ chain (Fig. S3 $\dagger$ ), and each bpy links two $\mathrm{Zn}$ atoms to form an infinite 1D zigzag chain. Then, two kinds of 1D chains cross-link together to give a undulating 2D network of 4 (Fig. 3b). The framework 4 can also be represented as a uninodal 4-connected sql/Shubnikov net with the point symbol $\left\{4^{4} \cdot 6^{2}\right\}$.

\section{Crystal structure of 5}

Single-crystal X-ray analysis reveals that the complex $\mathbf{5}$ crystallizes in a monoclinic system with space group $P 2_{1} / c$. There are one $\mathrm{Zn}(\mathrm{II})$ ion, one EtOip, one bpe ligands and one water molecule in the asymmetric unit. As shown in Fig. 4a, the Zn(II) ion is four-coordinated by two oxygen atoms from different EtOip ligands and two nitrogen atoms from two distinct bpe ligands, thus showing a distorted tetrahedral coordination $\left[\mathrm{ZnN}_{2} \mathrm{O}_{2}\right]$ geometry. The $\mathrm{Zn}-\mathrm{O}$ [1.979(3)-

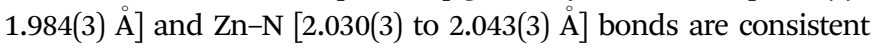
with related literature data. Each $\mathrm{Zn}$ (II) ion bridges two EtOip ligands and two bpe ligands to form a network with large rectangular windows (Fig. 4b). Framework 5 can also be viewed as a 4-connected sql/Shubnikov tetragonal plane net with the point symbol $\left\{4^{4} \cdot 6^{2}\right\}$. Moreover, adjacent separate nets are further interpenetrated with each other, resulting in a threefold 2D interpenetrating tri-layer architecture (Fig. 4c).
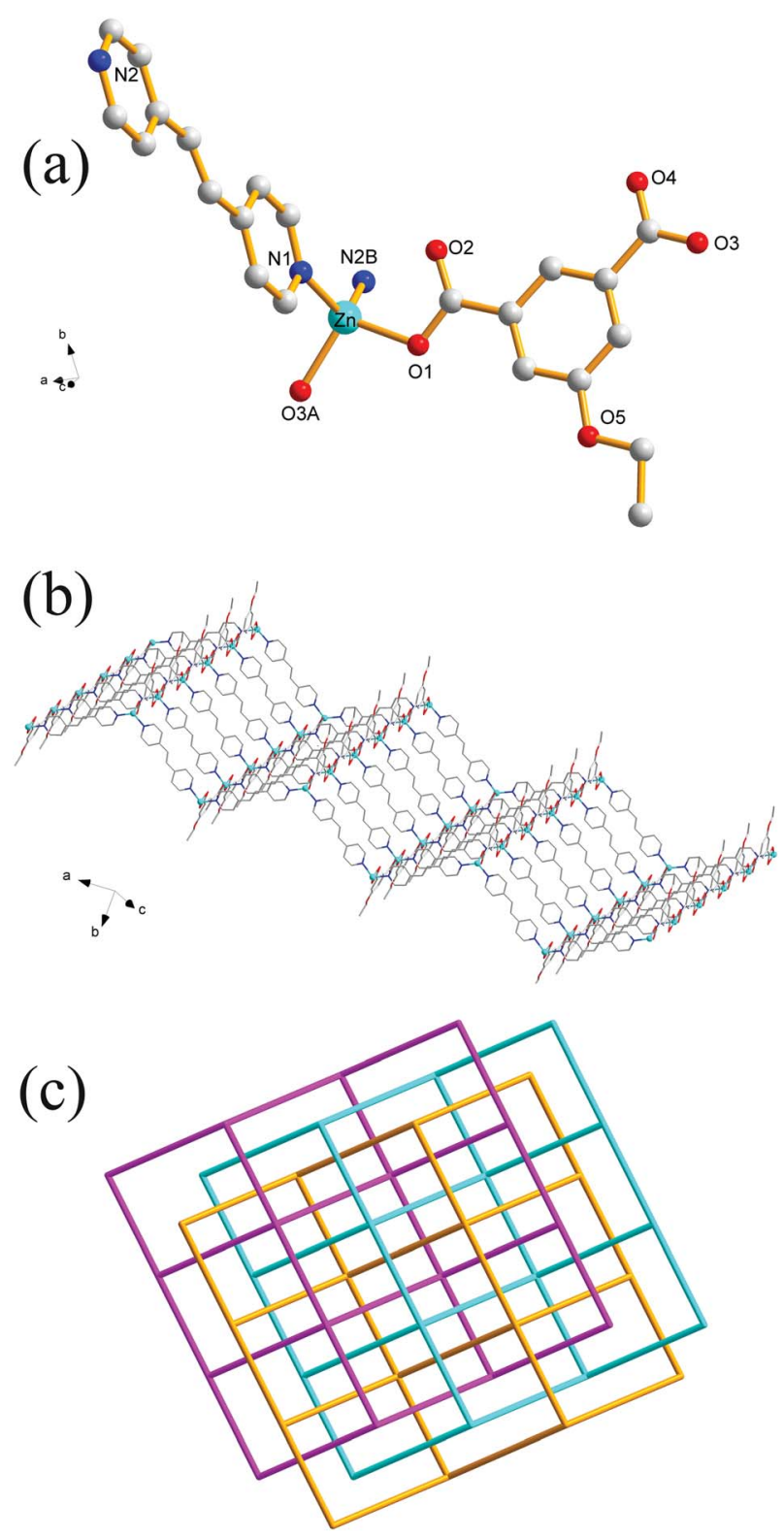

Fig. 4 (a) Coordination environment of the Zn(॥) centers in 5 with the hydrogen atoms and solvent molecules omitted for clarity (symmetric codes: (A) $x+1, y, z+1$ and (B) $x-1,-y+1 / 2, z+1 / 2$ ). (b) View of the $2 \mathrm{D}[\mathrm{Zn} \text { (EtOip)(bpe) }]_{n}$ network of 5 . (c) The $2 \mathrm{D}+2 \mathrm{D}+2 \mathrm{D} \rightarrow 2 \mathrm{D}$ interpenetration network in 5 . 


\section{Crystal structure of 6}

Different from 5, complex 6 crystallizes in the triclinic crystal system with $P \overline{1}$ space group. The asymmetric unit consists of one $\mathrm{Zn}$ (II) ion, one PrOip ligand and two half of bpe ligands with an inversion centre at the midpoint of the central $\mathrm{C}=\mathrm{C}$ bond as well as one water molecule. As shown in Fig. $5 \mathrm{a}$, the $\mathrm{Zn}$ center is also four-coordinated and features a distorted tetrahedral $\left[\mathrm{ZnO}_{2} \mathrm{~N}_{2}\right]$ geometry, which is bonded by two oxygen atoms originating from different PrOip ligands and two nitrogen atoms belonging to two distinct bpe ligands. The $\mathrm{Zn}-\mathrm{O}$ [1.9264(19) to 1.939(2) $\AA$ ] bond distances in 6 are shorter than that of 5. The $\mathrm{Zn}-\mathrm{N}$ bond length [2.048(2) to 2.068(3) $\AA$ ] in 6 is slightly longer than that of 5 . In 6, a pair of $\mathrm{Zn}$ atoms are bridged by PrOip ligands via a bis-monodentate coordination mode to form a [Zn(PrOip) $]_{n}$ chain along the $c$ axis (Scheme 1(I) and Fig. S5 $\dagger$ ). Such a chain is further connected by bpe ligands to yield a 2D wrinkled layer (Fig. 5b). In addition, the

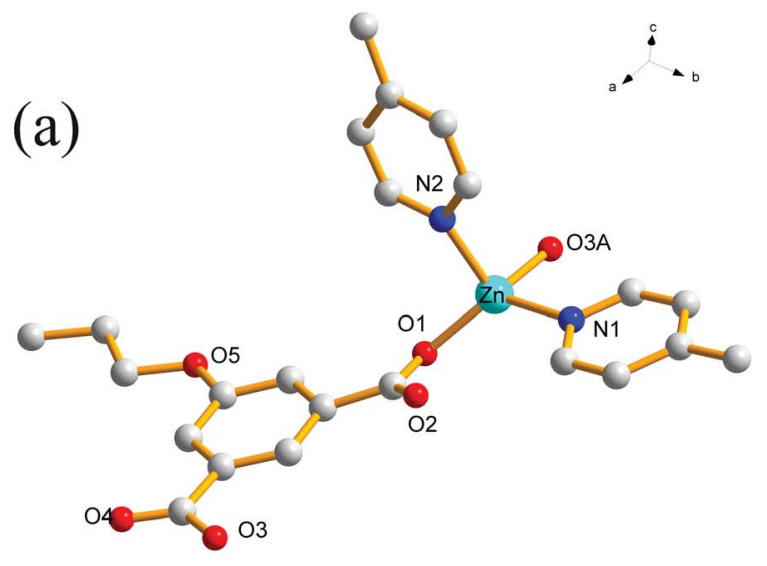

(b)

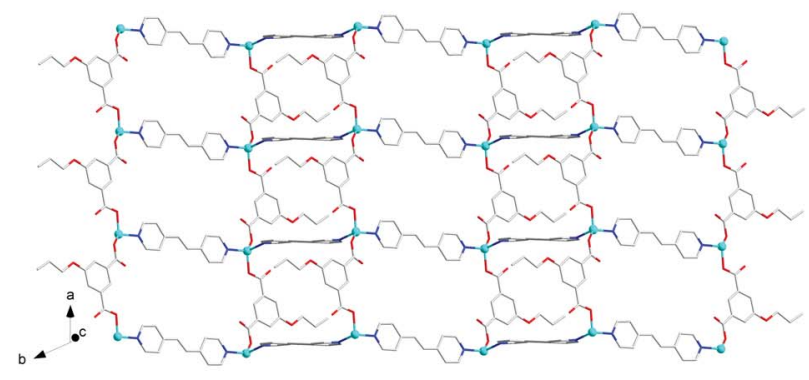

(c)

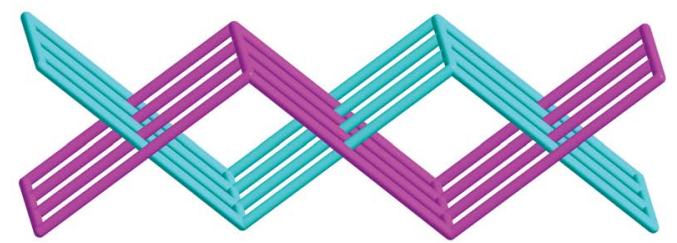

Fig. 5 (a) Coordination environment of the Zn(II) centers in 6 with the hydrogen atoms and solvent molecules omitted for clarity (symmetric codes: (A) $x-1, y, z)$. (b) View of the 2D [Zn(PrOip)(bpe) $]_{n}$ network of 6 . (c) The 2D $+2 \mathrm{D} \rightarrow 2 \mathrm{D}$ interpenetration network in 6 . (a)

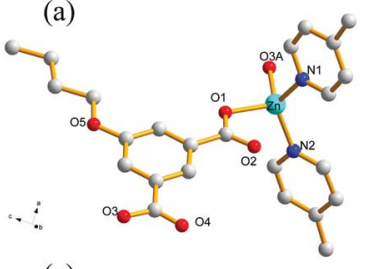

(c)

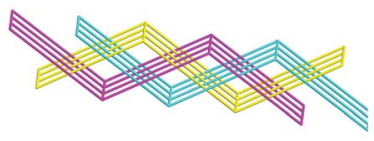

(b)

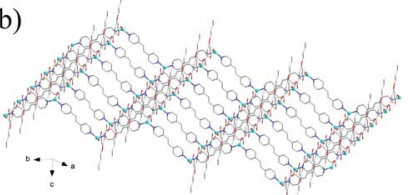

(d)

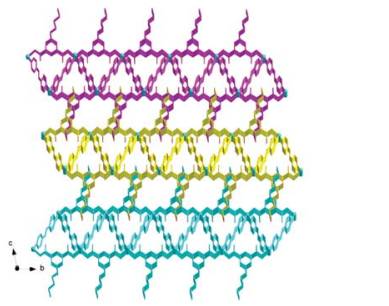

Fig. 6 (a) Coordination environment of the Zn(॥) centers in 7 with the hydrogen atoms and solvent molecules omitted for clarity (symmetric codes: (A) $x+1, y+1, z)$. (b) View of the $2 \mathrm{D}\left[\mathrm{Zn}\left({ }^{\mathrm{n}} \mathrm{BuOip}\right)(\mathrm{bpe})\right]_{n}$ network of 7. (c) The $2 D+2 D+2 D \rightarrow 2 D$ interpenetration network in 7. (d) 3D supramolecular structure based on $\mathrm{C}-\mathrm{H} \cdots \pi$ interaction in 7 .

rectangular windows of 6 are filled with another independent net, generating a $2 \mathrm{D}+2 \mathrm{D} \rightarrow 2 \mathrm{D}$ interpenetration bi-layer structure with a $\left\{4^{4} \cdot 6^{2}\right\}$ topology, instead of the threefold interpenetrated framework of 5 (Fig. 5 c).

\section{Crystal structure of 7}

Compound 7 also crystallizes in the triclinic crystal system with $P \overline{1}$ space group. The asymmetric unit of 7 contains one $\mathrm{Zn}$ (II) ion, one ${ }^{n}$ BuOip ligand and two half of bpe ligands which has an inversion center at the midpoint of the central $\mathrm{C}=\mathrm{C}$ bond as well as a half of DMF molecules which confirmed by elemental and thermogravimetric analyses. In 7, the distorted tetrahedral $\mathrm{Zn}$ center is coordinated to two oxygen atoms from two ${ }^{n}$ BuOip ligands and two nitrogen atoms from two bpe molecules

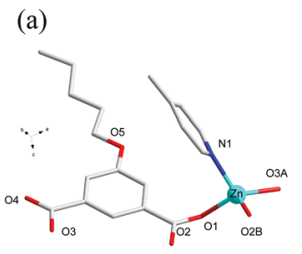

(c)

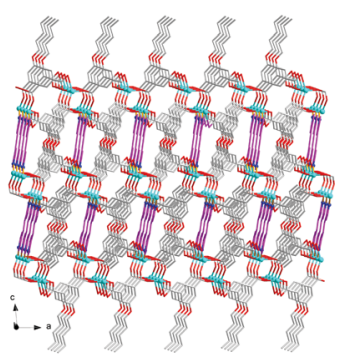

(b)

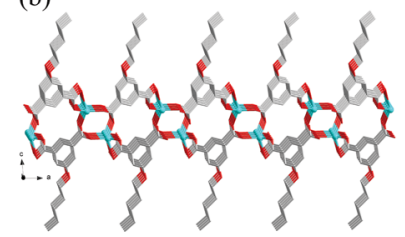

(d)

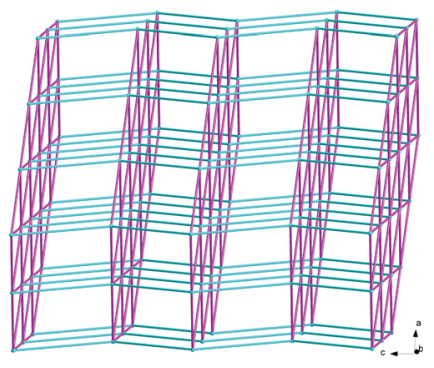

Fig. 7 (a) Coordination environment of the Zn(II) centers in 8 with the hydrogen atoms omitted for clarity (symmetric codes: (A) $x+1 / 2, y-$ $1 / 2, z$ and (B) $-x, y,-z+1 / 2$ ). (b) The $2 D$ layer constructed from ${ }^{n}$ PeOip ligands and $\mathrm{Zn}(\mathrm{II})$ ions. (c) View of the $3 \mathrm{D}\left[\mathrm{Zn}\left({ }^{n} \mathrm{PeOip}\right)(\mathrm{bpe})\right]_{n}$ coordination network of 8 . (d) View of the topological net of 8 . 


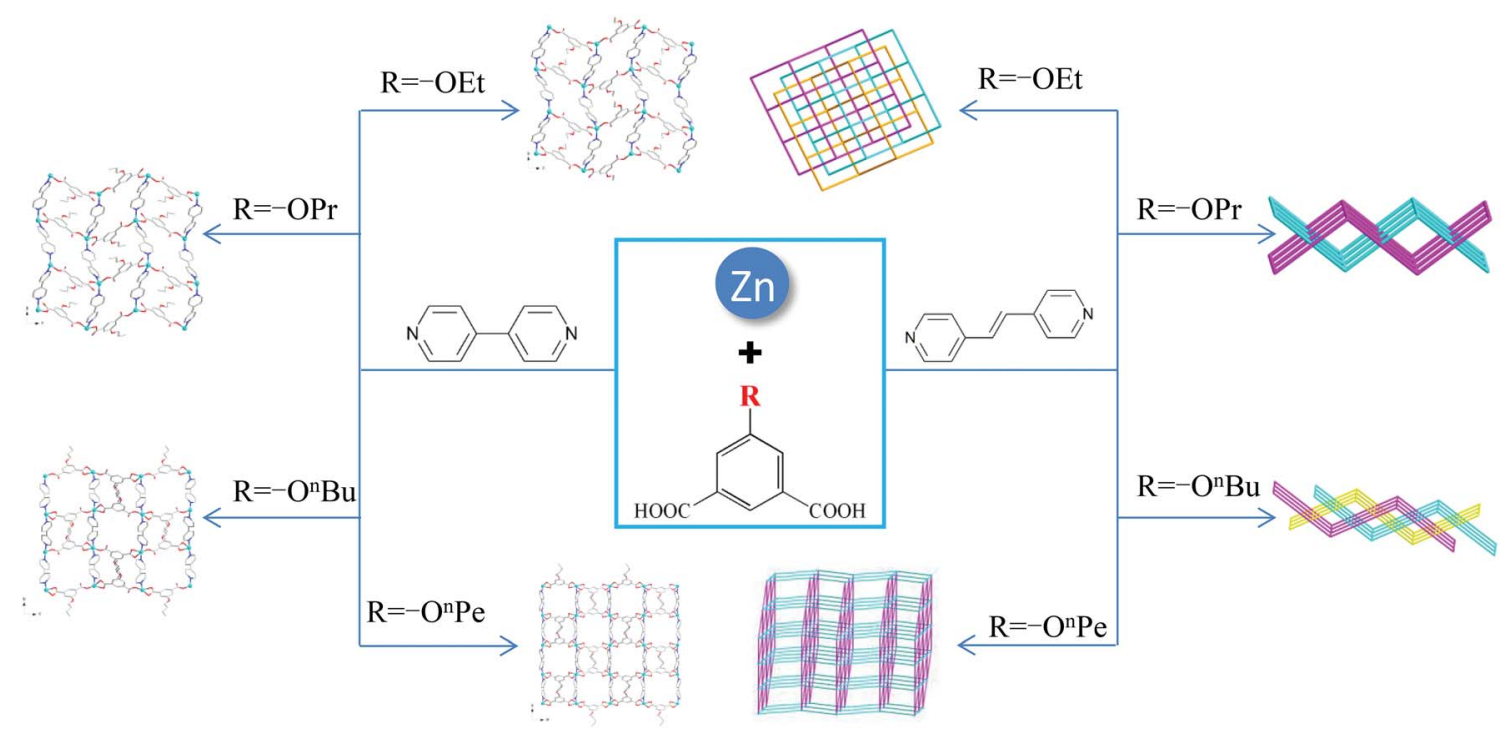

Scheme 2 Summary of crystal structures in complexes 1-8.

(Fig. 6a). The $\mathrm{Zn}-\mathrm{O}[1.978(2)-1.980(2) \AA]$ and $\mathrm{Zn}-\mathrm{N}[2.035(2)-$ 2.037(2) $\AA$ ] bond distances of 7 are similar with that of 5 . Each ${ }^{n}$ BuOip ligand bridges a pair of $\mathrm{Zn}$ atoms via bis-monodentate coordination mode, to form a $1 \mathrm{D}\left[\mathrm{Zn}\left({ }^{n} \mathrm{BuOip}\right)\right]_{n}$ chain extending along the $c$ axis (Scheme 1(III) and Fig. S6†). Each bpe ligand links the $\mathrm{Zn}$ center in one chain to another $\mathrm{Zn}$ center in an adjacent chain, forming a $2 \mathrm{D}$ wrinkle-like $\left[\mathrm{Zn}\left({ }^{n} \mathrm{BuOip}\right)(\mathrm{bpe})\right]_{n}$ net with large rectangular windows (Fig. 6b). Furthermore, three adjacent networks interlock with each other to give a threefold interpenetrating architecture with a $\left\{4^{4} \cdot 6^{2}\right\}$ topology (Fig. 6c). It is noted worth that the interpenetrating fashions of 7 is slightly different from 5 due to the structure of 7 containing two types of bpe linkers. Interestingly, adjacent tri-layers in 7 connect with each other through $\mathrm{C}-\mathrm{H} \cdots \pi$ interactions to form a supramolecular 3D network (Fig. 6d) with a free volume of 18.6\% (229.7 $\AA^{3}$ out of the $1237.7 \AA^{3}$ unit cell volume) by using PLATON. ${ }^{66}$

\section{Crystal structure of 8}

Compound 8 crystallizes in the monoclinic system with the space group $C 2 / c$. The asymmetric unit of $\mathbf{8}$ is made up of one $\mathrm{Zn}(\mathrm{II})$ ion, one ${ }^{n}$ PeOip and half of bpe. The four-coordinated $\mathrm{Zn}$ center is satisfied by three oxygen atoms from three different ${ }^{n}$ PeOip ligands and one nitrogen atom belonging to bpe, forming a distorted tetrahedral coordination $\left[\mathrm{ZnN}_{1} \mathrm{O}_{3}\right]$ geometry (Fig. 7a). The Zn-O [1.9094(17) A to 1.9831(17) §] and Zn-N [2.0458(19) $\AA]$ distances are within typical values encountered in related Zn(II) derivatives. In this structure, two adjacent $\mathrm{Zn}$ atoms of the same crystallography are combined together by two bis(monodentate) carboxylates to yield a bimetallic unit $\left[\mathrm{Zn}_{2}\left(\mathrm{RCO}_{2}\right)_{2}\right]$, in which the non-bonding distance of $\mathrm{Zn}_{1} \cdots \mathrm{Zn}_{1}$ is $3.825 \AA$ (Scheme $1(\mathrm{~V})$ and Fig. S7†). The uniform bimetallic units are linked together by ${ }^{n}$ PeOip ligands to build a $2 \mathrm{D}$ layer (Fig. 7b). Each bpe ligand connects two $\mathrm{Zn}$ atoms from the adjacent $2 \mathrm{D}$ layers and extends the $2 \mathrm{D}$ layer substructures into a porous 3D framework (Fig. 7c). If the bimetallic units $\left[\mathrm{Zn}_{2}\left(\mathrm{RCO}_{2}\right)_{2}\right]$ are considered as nodes, ${ }^{n}$ PeOip ligands and bpe ligands as linkages, topological analysis reveals that compound 8 exhibits a 6-connected topological structure with a $\left\{3^{3} \cdot 4^{3} \cdot 5^{5} \cdot 6^{4}\right\}$ point symbol (Fig. $7 d$ ).

\section{Effects of functionalized-groups of isophthalate and length of} $\mathrm{N}$-donor ligands on the structures of CPs

It is well known that the structural diversities and properties of CPs are undoubtedly related to the functionalized groups of isophthalate derivative ligands, even though they are not involved in coordination with metal ions. As shown in Scheme 2, the reaction of EtOip, bpy, and Zn(II) yielded a 2D layer (complex 1); similar structural framework were obtained when EtOip was replaced by PrOip (complex 2). When the PrOip ligand was replaced by ${ }^{n}$ BuOip complex 3 were obtained; similar structural networks were obtained when the ${ }^{n}$ PeOip ligand was used in the synthesis systems (complex 4). These results show that the EtO/PrO and ${ }^{n} \mathrm{BuO} /{ }^{n} \mathrm{PeO}$ functionalized-groups do not

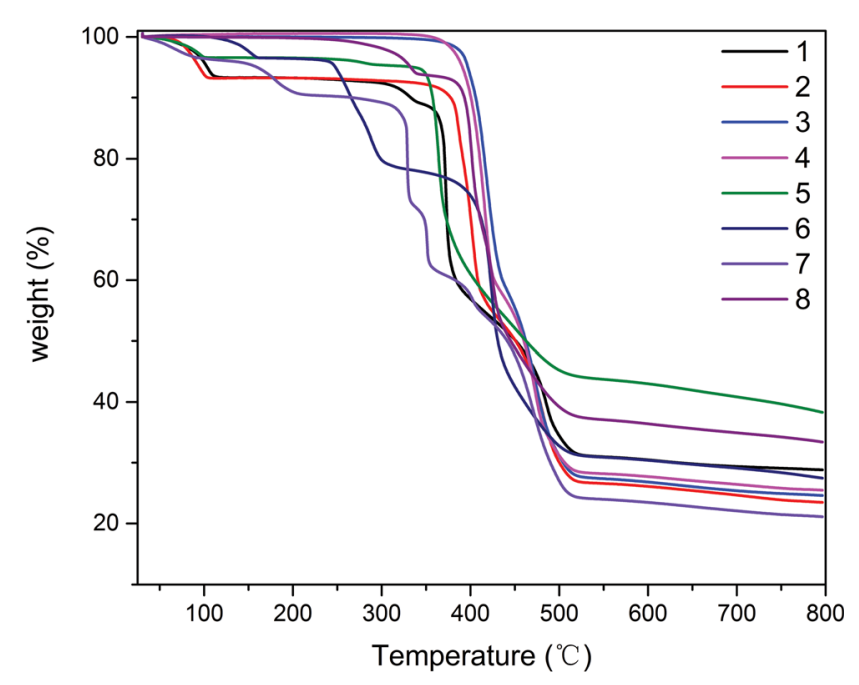

Fig. 8 TGA curves of complexes 1-8. 


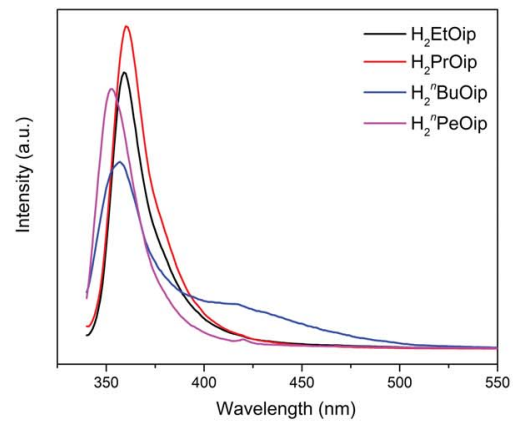

(a)

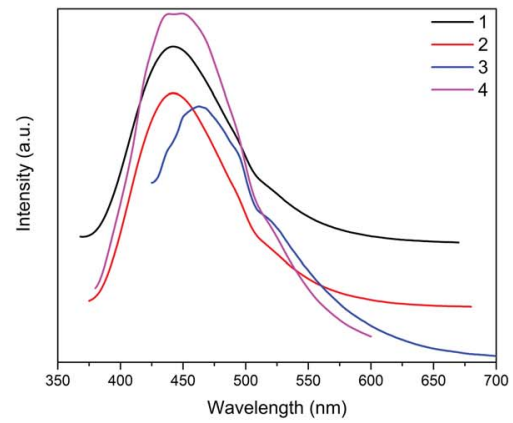

(b)

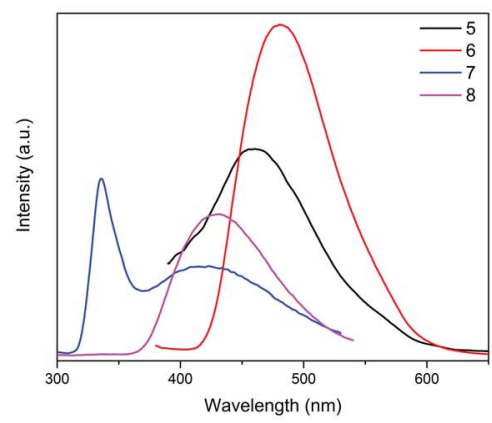

(c)

Fig. 9 (a) The luminescence emission curves of free 5-functionalized isophthalate ligands (b) the luminescence emission curves of 1-4. (c) The luminescence emission curves of 5-8.

substantially affect the structural diversities of the resultant CPs. In comparison with bpy, bpe possessed distinct features (length), which would adjust the structural diversities and properties of the resultant CPs. The hydrothermal reaction of EtOip, bpe and Zn(II) produced complex 5, with a structural framework is similar to that of MeOip ${ }^{35}$ a slight variation of the functionalized-group from EtO to PrO resulted in the formation of a twofold interpenetrating 4-connected 2D framework (complex 6). A threefold interpenetrating 2D network (complex 7) is generated when the ${ }^{n} \mathrm{BuO}$ group has inserts into the isophthalic group. Interestingly, when the functionalized-group ${ }^{n} \mathrm{BuO}$ was replaced with ${ }^{n} \mathrm{PeO}$ a non-interpenetrating 6-connected 3D framework (complex 8) were obtained. Evidently, the diverse structures of CPs 5-8 are seriously affected by the 5functionalized groups of isophthalate derivative ligands. Although CPs $\mathbf{1}$ and 5, 2 and 6, 3 and 7, as well as $\mathbf{4}$ and $\mathbf{8}$ were prepared under similar reaction conditions except for the length of dipyridyl ligands used, distinct coordination frameworks were obtained. These results clearly demonstrated that different features of $\mathrm{N}$-containing ligands (length) play a crucial role in determining the molecular structures of the resulting CPs.

\section{Thermal stability and PXRD}

The phase purities of 1-8 can be confirmed by powder X-ray diffraction (PXRD) patterns, which are in excellent agreement with the corresponding simulated ones (Fig. S9广), indicating the purity of the synthesized material and the as-simulated crystals. The thermal stability of compounds 1-8 was also studied by thermogravimetric analysis (TGA) in the $25-800{ }^{\circ} \mathrm{C}$ temperature range under $\mathrm{N}_{2}$ atmosphere. The obtained TGA curves for 1-8 are shown in Fig. 8. Compound 1 shows the loss of two crystallization water molecules (exptl, 7.9\%; calcd, $8.1 \%$ ) in the $50-$ $115{ }^{\circ} \mathrm{C}$ range, followed by decomposition which begins at $300^{\circ} \mathrm{C}$. Compound 2 displays the removal of two crystallization water molecules in a temperature range from $60^{\circ} \mathrm{C}$ to $105^{\circ} \mathrm{C}$ (exptl, 7.2\%; calcd, 7.5\%), while a dehydrated sample then remains stable up to $\sim 350^{\circ} \mathrm{C}$. For compounds, 3,4 and 8 , which do not contain solvent molecules, TGA curves reveal that they are stable up to $350^{\circ} \mathrm{C}, 342{ }^{\circ} \mathrm{C}$ and $260^{\circ} \mathrm{C}$, respectively, followed by decomposition upon further heating. The TGA curve of 5 shows a release of one $\mathrm{H}_{2} \mathrm{O}$ molecule between $50{ }^{\circ} \mathrm{C}$ and $113{ }^{\circ} \mathrm{C}$ (exptl, 3.5\%; calcd, 3.9\%), after which the compound was stable up to around $330^{\circ} \mathrm{C}$ and then decomposed. In $\mathbf{6}$, a weight loss of approximately $3.6 \%$ corresponding to the loss of water molecules (calcd: $3.7 \%$ ) in a temperature range of $100-162{ }^{\circ} \mathrm{C}$, after which the compound was stable up to about $236^{\circ} \mathrm{C}$ and then the compound decomposed gradually. The TGA profile of compound 7 showed several stages of weight loss with a $7.5 \%$ loss in a temperature range of $50-220{ }^{\circ} \mathrm{C}$ corresponding to the loss of half of the DMF molecules (calcd: $7.7 \%$ ). Afterward the compound was stable up to around $300{ }^{\circ} \mathrm{C}$ and then the decomposed gradually over several steps.

\section{Solid state photoluminescence properties}

Taking into account the excellent luminescent properties of CPs with $d^{10}$ metal centers, ${ }^{6,7,67-70}$ the luminescence of the free 5functionalized isophthalate ligands and compounds 1-8 were investigated in the solid state at room temperature (Fig. 9). The free 5 -functionalized isophthalate ligand displays photoluminescence with emission maxima at $360 \mathrm{~nm}\left(\lambda_{\mathrm{ex}}=345 \mathrm{~nm}\right)$ for $\mathrm{H}_{2}$ EtOip, $360 \mathrm{~nm}\left(\lambda_{\text {ex }}=347 \mathrm{~nm}\right)$ for $\mathrm{H}_{2}$ PrOip, $357 \mathrm{~nm}\left(\lambda_{\text {ex }}=\right.$ $334 \mathrm{~nm})$ for $\mathrm{H}_{2}{ }^{n}$ BuOip and $353 \mathrm{~nm}\left(\lambda_{\mathrm{ex}}=339 \mathrm{~nm}\right)$ for $\mathrm{H}_{2}{ }^{n}$ PeOip, respectively, which may be assigned to the $\pi^{*} \rightarrow \mathrm{n}$ or $\pi^{*} \rightarrow \pi$ transitions. Compounds 1-8 exhibit fluorescence bands at $442 \mathrm{~nm}\left(\lambda_{\mathrm{ex}}=348 \mathrm{~nm}\right)$ for $1,442 \mathrm{~nm}\left(\lambda_{\mathrm{ex}}=353 \mathrm{~nm}\right)$ for 2 , $463 \mathrm{~nm}\left(\lambda_{\mathrm{ex}}=397 \mathrm{~nm}\right)$ for $3,442 \mathrm{~nm}\left(\lambda_{\mathrm{ex}}=325 \mathrm{~nm}\right)$ for 4 , $456 \mathrm{~nm}\left(\lambda_{\mathrm{ex}}=361 \mathrm{~nm}\right)$ for $5,482 \mathrm{~nm}\left(\lambda_{\mathrm{ex}}=357 \mathrm{~nm}\right)$ for 6 , $336 \mathrm{~nm}$ and $433 \mathrm{~nm}\left(\lambda_{\mathrm{ex}}=272 \mathrm{~nm}\right)$ for $7,433 \mathrm{~nm}\left(\lambda_{\mathrm{ex}}=272 \mathrm{~nm}\right)$ for $\mathbf{8}$, respectively. It is well known that $\mathrm{Zn}$ (II) ions is difficult to oxidize or reduce due to its $d^{10}$ configuration. Thus, the emissions of complexes 1-8 are neither metal-to-ligand charge transfer (MLCT) nor ligand-to-metal charge transfer (LMCT), which may be ascribed to a mixture character of intraligand and ligand-to-ligand charge transition (LLCT).

\section{Conclusions}

In this work, eight Zn(II) coordination polymers have been successfully synthesized under hydrothermal conditions by the 
reaction of 5-functionalized isophthalate acids and dipyridyl ligands with $\mathrm{Zn}$ (II) salts. Although the 5-functionalized groups of isophthalate derivatives are not involved in coordination with $\mathrm{Zn}$ (II) ions, their stericity and number of carbon atoms demonstrated significant effects on structural diversity, thermal stability and photoluminescent properties of the resultant CPs. These complexes show diverse structures varying from $2 \mathrm{D}$ to $3 \mathrm{D}$ frameworks. The variety of the structures indicates that 5functionalized groups of isophthalate and the length of rigid dipyridyl ligands play a crucial important role in the selfassembly of CPs. Moreover, the thermal stabilities and photoluminescence properties were also studied. The results imply that these compounds are potential luminescent materials.

\section{Conflicts of interest}

The authors declare no competing financial interest.

\section{Acknowledgements}

This work was supported by the National Natural Science Foundation of China (Projects 21461029 and 21561033). We are grateful for the useful comments of the editor and reviewers.

\section{References}

1 A. Schoedel, M. Li, D. Li, M. O'Keeffe and O. M. Yaghi, Chem. Rev., 2016, 116, 12466-12535.

2 V. Guillerm, L. J. Weselinski, Y. Belmabkhout, A. J. Cairns, V. D'Elia, L. Wojtas, K. Adil and M. Eddaoudi, Nat. Chem., 2014, 6, 673-680.

3 M. D. Allendorf, C. A. Bauer, R. K. Bhakta and R. J. T. Houk, Chem. Soc. Rev., 2009, 38, 1330-1352.

4 K. P. Carter, A. M. Young and A. E. Palmer, Chem. Rev., 2014, 114, 4564-4601.

5 Y. Cui, Y. Yue, G. Qian and B. Chen, Chem. Rev., 2012, 112, 1126-1162.

6 W. P. Lustig, S. Mukherjee, N. D. Rudd, A. V. Desai, J. Li and S. K. Ghosh, Chem. Soc. Rev., 2017, 46, 3242-3285.

7 Y. Cui, B. Li, H. He, W. Zhou, B. Chen and G. Qian, Acc. Chem. Res., 2016, 49, 483-493.

8 I. Nath, J. Chakraborty and F. Verpoort, Chem. Soc. Rev., 2016, 45, 4127-4170.

9 M. Zhao, K. Yuan, Y. Wang, G. Li, J. Guo, L. Gu, W. Hu, H. Zhao and Z. Tang, Nature, 2016, 539, 76-80.

10 N. C. Burtch and K. S. Walton, Acc. Chem. Res., 2015, 48, 2850-2857.

11 J.-R. Li, J. Sculley and H.-C. Zhou, Chem. Rev., 2012, 112, 869932.

12 N. Yanai, W. Kaneko, K. Yoneda, M. Ohba and S. Kitagawa, J. Am. Chem. Soc., 2007, 129, 3496-3497.

13 H. Furukawa, K. E. Cordova, M. O'Keeffe and O. M. Yaghi, Science, 2013, 341, 1230444.

14 M. D. Lankshear and P. D. Beer, Coord. Chem. Rev., 2006, 250, 3142-3160.

15 L. Ma and W. Lin, J. Am. Chem. Soc., 2008, 130, 13834-13835.
16 B. Zheng, H. Dong, J. Bai, Y. Li, S. Li and M. Scheer, J. Am. Chem. Soc., 2008, 130, 7778-7779.

17 J.-B. Lin, J.-P. Zhang, W.-X. Zhang, W. Xue, D.-X. Xue and X.-M. Chen, Inorg. Chem., 2009, 48, 6652-6660.

18 S.-L. Li, K. Tan, Y.-Q. Lan, J.-S. Qin, M.-N. Li, D.-Y. Du, H.-Y. Zang and Z.-M. Su, Cryst. Growth Des., 2010, 10, 1699-1705.

19 C.-P. Li and M. Du, Chem. Commun., 2011, 47, 5958-5972.

20 Z. Su, M. Chen, T.-a. Okamura, M.-S. Chen, S.-S. Chen and W.-Y. Sun, Inorg. Chem., 2011, 50, 985-991.

21 Y. Zhang, J. Yang, Y. Yang, J. Guo and J.-F. Ma, Cryst. Growth Des., 2012, 12, 4060-4071.

22 D. K. Maity, A. Halder, B. Bhattacharya, A. Das and D. Ghoshal, Cryst. Growth Des., 2016, 16, 1162-1167.

23 J.-W. Cui, W.-J. An, K. Van Hecke and G.-H. Cui, Dalton Trans., 2016, 45, 17474-17484.

24 Y. Mu, G. Han, Z. Li, X. Liu, H. Hou and Y. Fan, Cryst. Growth Des., 2012, 12, 1193-1200.

25 J. Yang, J.-F. Ma, Y.-Y. Liu, J.-C. Ma and S. R. Batten, Inorg. Chem., 2007, 46, 6542-6555.

26 S. Henke, A. Schneemann, S. Kapoor, R. Winter and R. A. Fischer, J. Mater. Chem., 2012, 22, 909-918.

27 S. Henke and R. A. Fischer, J. Am. Chem. Soc., 2011, 133, 2064-2067.

28 A. Schneemann, Y. Takahashi, R. Rudolf, S.-i. Noro and R. A. Fischer, J. Mater. Chem. A, 2016, 4, 12963-12972.

29 L.-H. Cao, H.-Y. Li, H. Xu, Y.-L. Wei and S.-Q. Zang, Dalton Trans., 2017, 46, 11656-11663.

30 L. H. Cao, F. Shi, W. M. Zhang, S. Q. Zang and T. C. Mak, Chem.-Eur. J., 2015, 21, 15705-15712.

31 H. Sato, W. Kosaka, R. Matsuda, A. Hori, Y. Hijikata, R. V. Belosludov, S. Sakaki, M. Takata and S. Kitagawa, Science, 2014, 343, 167-170.

32 A. Schneemann, R. Rudolf, S. Henke, Y. Takahashi, H. Banh, I. Hante, C. Schneider, S. I. Noro and R. A. Fischer, Dalton Trans., 2017, 46, 8198-8203.

33 X. Li, Z. Yu, T. Guan, X. Li, G. Ma and X. Guo, Cryst. Growth Des., 2015, 15, 278-290.

34 Y. Su, X. Li, X. Li, H. Pan and R. Wang, CrystEngComm, 2015, 17, 4883-4894.

35 L.-F. Ma, B. Li, X.-Y. Sun, L.-Y. Wang and Y.-T. Fan, Z. Anorg. Allg. Chem., 2010, 636, 1606-1611.

36 B. Gole, A. K. Bar and P. S. Mukherjee, Chem.-Eur. J., 2014, 20, 13321-13336.

37 B. Gole, A. K. Bar and P. S. Mukherjee, Chem.-Eur. J., 2014, 20, 2276-2291.

38 H. Sato, R. Matsuda, M. H. Mir and S. Kitagawa, Chem. Commun., 2012, 48, 7919-7921.

39 L. J. McCOrmick, S. A. Morris, A. M. Z. Slawin, S. J. Teat and R. E. Morris, Cryst. Growth Des., 2016, 16, 5771-5780.

40 Y. Sha, S. Bai, J. Lou, D. Wu, B. Liu and Y. Ling, Dalton Trans., 2016, 45, 7235-7239.

41 Q. Yang, S. Ren, Y. Hao, Q. Zhao, Z. Chen and H. Zheng, Inorg. Chem., 2016, 55, 4951-4957.

42 H.-Y. Li, L.-H. Cao, Y.-L. Wei, H. Xu and S.-Q. Zang, CrystEngComm, 2015, 17, 6297-6307. 
43 C. X. Bezuidenhout, V. J. Smith, P. M. Bhatt, C. Esterhuysen and L. J. Barbour, Angew. Chem., Int. Ed., 2015, 54, 20792083.

44 B. Gole, U. Sanyal and P. S. Mukherjee, Chem. Commun., 2015, 51, 4872-4875.

45 K. Hirai, K. Chen, T. Fukushima, S. Horike, M. Kondo, N. Louvain, C. Kim, Y. Sakata, M. Meilikhov, O. Sakata, S. Kitagawa and S. Furukawa, Dalton Trans., 2013, 42, 15868-15872.

46 T. Fukushima, S. Horike, H. Kobayashi, M. Tsujimoto, S. Isoda, M. L. Foo, Y. Kubota, M. Takata and S. Kitagawa, J. Am. Chem. Soc., 2012, 134, 13341-13347.

47 Y. Hijikata, S. Horike, D. Tanaka, J. Groll, M. Mizuno, J. Kim, M. Takata and S. Kitagawa, Chem. Commun., 2011, 47, 76327634.

48 R. K. Feller and A. K. Cheetham, CrystEngComm, 2009, 11, 980.

49 R. K. Feller and A. K. Cheetham, Dalton Trans., 2008, 0, 20342042.

50 Z. Shi, G. Li, L. Wang, L. Gao, X. Chen, J. Hua and S. Feng, Cryst. Growth Des., 2004, 4, 25-27.

51 X.-Y. Duan and M.-L. Wei, Cryst. Growth Des., 2017, 17, 11971207.

52 B. Mu and R.-D. Huang, CrystEngComm, 2016, 18, 986-999.

53 C. S. Hawes, G. P. Knowles, A. L. Chaffee, K. F. White, B. F. Abrahams, S. R. Batten and D. R. Turner, Inorg. Chem., 2016, 55, 10467-10474.

54 C. S. Hawes, N. F. Chilton, B. Moubaraki, G. P. Knowles, A. L. Chaffee, K. S. Murray, S. R. Batten and D. R. Turner, Dalton Trans., 2015, 44, 17494-17507.

55 L.-Y. Xin, G.-Z. Liu, X.-L. Li and L.-Y. Wang, Cryst. Growth Des., 2012, 12, 147-157.
56 S. Horike, K. Kishida, Y. Watanabe, Y. Inubushi, D. Umeyama, M. Sugimoto, T. Fukushima, M. Inukai and S. Kitagawa, J. Am. Chem. Soc., 2012, 134, 9852-9855.

57 C. M. Nagaraja, R. Haldar, T. K. Maji and C. N. R. Rao, Cryst. Growth Des., 2012, 12, 975-981.

58 B. Chen, Y. Ji, M. Xue, F. R. Fronczek, E. J. Hurtado, J. U. Mondal, C. Liang and S. Dai, Inorg. Chem., 2008, 47, 5543-5545.

59 M. H. Mir, S. Kitagawa and J. J. Vittal, Inorg. Chem., 2008, 47, 7728-7733.

60 L.-F. Ma, Q.-L. Meng, C.-P. Li, B. Li, L.-Y. Wang, M. Du and F.-P. Liang, Cryst. Growth Des., 2010, 10, 3036-3043.

61 Q. Chu, Z. Su, J. Fan, T.-a. Okamura, G.-C. Lv, G.-X. Liu, W.-Y. Sun and N. Ueyama, Cryst. Growth Des., 2011, 11, 3885-3894.

62 H. Abourahma, G. J. Bodwell, J. Lu, B. Moulton, I. R. Pottie, R. B. Walsh and M. J. Zaworotko, Cryst. Growth Des., 2003, 3, 513-519.

63 G. M. Sheldrick, SADABS, Program for Area Detector Adsorption Correction, Institute for Inorganic Chemistry, University of Göttingen, Germany, 1996.

64 G. M. Sheldrick, Acta Crystallogr., Sect. C: Struct. Chem., 2015, C71, 3-8.

65 A. L. Spek, Acta Crystallogr., Sect. C: Struct. Chem., 2015, C71, 9-18.

66 A. L. Spek, J. Appl. Crystallogr., 2003, 36, 7-13.

67 X. Feng, J. Wang, B. Liu, L. Wang, J. Zhao and S. Ng, Cryst. Growth Des., 2012, 12, 927-938.

68 X. Feng, X. L. Ling, L. Liu, H. L. Song, L. Y. Wang, S. W. Ng and B. Y. Su, Dalton Trans., 2013, 42, 10292-10303.

69 X. Feng, Y. Q. Feng, L. Liu, L. Y. Wang, H. L. Song and S. W. Ng, Dalton Trans., 2013, 42, 7741-7754.

70 X. Feng, Y. Feng, N. Guo, Y. Sun, T. Zhang, L. Ma and L. Wang, Inorg. Chem., 2017, 56, 1713-1721. 